\title{
Determinación de la tipología social, ambiental, institucional y económica de la gestión integrada de los residuos sólidos
}

\author{
Gustavo Adolfo García Macz \\ Candidato a Doctor del Programa DOCINADE -UNED- \\ Licenciado en Ciencias Agrícolas \\ M. Sc. en Gerencia para el Desarrollo Sostenible \\ ingusma@gmail.com \\ Profesor Titular \\ Centro Universitario del Norte \\ Universidad de San Carlos de Guatemala \\ Gesly Anibal Bonilla Landaverry \\ Ingeniero Agrónomo, Maestro en Ciencias en Gestión Ambiental y \\ Doctor en Ciencias Políticas y Sociología \\ gesly77@hotmail.com \\ Centro Universitario de Sur Oriente \\ Universidad de San Carlos de Guatemala
}

Fecha de recepción: 12/01/2016 Fecha de aceptación: 17/07/2017

\begin{abstract}
Resumen
El siguiente artículo presenta los resultados de una investigación que determinó la tipología social, ambiental, institucional y económica sobre la gestión integrada de los residuos sólidos -GIRS-, en Cobán, Alta Verapaz, Guatemala. La metodología utilizada en esta investigación fue autorizada por el Instituto de Agricultura, Recursos Naturales y Ambiente -IARNA- de la Universidad Rafael Landívar de Guatemala, diseñada y adaptada para las condiciones nacionales y de aplicación local, e implementada en este municipio de etnia Q'eqchí. Con el desarrollo de la presente investigación se pretende sugerir a las autoridades municipales acerca de la necesidad de implementar métodos alternativos al manejo de la basura porque puede provocar grandes daños a la salud de los seres humanos, contamina el ambiente y reduce la belleza del entorno. Es conveniente retomar los valores y principios ambientales de la población a través de la educación para que mejoren su conducta frente al ambiente y el daño que causa la basura. La idea básica es orientar a los usuarios a separar los materiales recuperables que son retirados en forma especial y conducidos a industrias que los utilizan como materia prima para la elaboración de sus productos, lográndose obtener beneficios económicos.
\end{abstract}

\section{Palabras clave}

Gestión integral de residuos sólidos, contaminación, manejo de residuos sólidos, vertedero municipal

\begin{abstract}
The following article presents the results of an investigation that determined the social, environmental, institutional and economic typology of the integrated solid waste management -GIRS- in Cobán, Alta Verapaz, Guatemala. The methodology used in this research was authorized by the Institute of Agriculture Natural Resources and Environment -|ARNA- of the Rafael Landivar University of Guatemala, designed and adapted to national conditions and local application, and implemented in the municipality of ethnic Q'eqchí. The goal of this research is to suggest to the municipal authorities about the need to implement alternative approaches to waste management because it can cause great harm to the health of humans, pollutes the environment and reduces beauty environment. It is convenient return to the values and environmental principles of the population through education to improve their behavior towards the environment and the damage caused by waste. The basic idea is to guide users to separate the recoverable materials are removed in a special way and led to industries that use them as raw material for the manufacture of its products, achieving economic benefits.
\end{abstract}

\section{Keywords:}

Comprehensive management of solid waste, pollution, solid waste management, municipal landfill 


\section{Introducción}

Los principales actores involucrados en lo relacionado a los residuos sólidos son el municipio, la ciudadanía y el sector productivo privado. Sin embargo, hasta el momento no se cuenta con un estudio sistematizado sobre la situación actual de la Gestión Integral de los Residuos Sólidos -GIRS-, lo que sería de mucha utilidad para los tomadores de decisiones y de esa cuenta plantear una propuesta viable para el manejo, control y administración de los residuos sólidos que propiciará una mejora ambiental y por ende será de beneficio para la población en general.

El presente trabajo muestra el estudio que se realizó en la cabecera municipal de Cobán, en el departamento de Alta Verapaz. Las variables estudiadas fueron el manejo de los residuos sólidos -RS- en los hogares, tren de limpieza municipal, depósitos clandestinos de RS, RS en las calles, la opinión de la población acerca del estado actual y sugerencias de las personas y otras que se identifiquen en el proceso.

En Cobán se encuentra un basurero municipal donde las personas que recolectan materiales del contenido vertido, ya que esto representa un medio de subsistencia, pero el resto de los residuos sólidos, tanto orgánicos como inorgánicos vuelve a quedar mezclado, sin tratamiento. Con el correr del tiempo y en época de verano se originan incendios que producen contaminación y generan altas concentraciones de $\mathrm{CO}_{2}$, y otras emanaciones como gas metano, etano y propano, que generan material altamente combustible que a la vez de provocar polución generan peligro para la población cercana. Durante la carga y transporte de los desechos, los envases se rompen al manejarlos, además de que algunas bolsas se caen y quedan en la ruta, por lo que también los recolectores se constituyen en contaminadores de las vías de acceso.

Con los resultados obtenidos se pretende dar a conocer a las autoridades municipales acerca de la necesidad de implementar métodos alternativos al manejo de la basura porque puede provocar grandes daños a la salud de los seres humanos, contamina el ambiente y reduce la belleza del entorno.
Es conveniente retomar los valores y principios ambientales de la población a través de la educación para que mejoren su conducta frente al ambiente y el daño que causa la basura. La idea básica es orientar a los usuarios a separar los materiales recuperables que son retirados en forma especial y conducidos a industrias que los utilizan como materia prima para la elaboración de sus productos, lográndose obtener beneficios económicos.

\section{Marco teórico}

\subsection{El municipio y su papel en la gestión ambiental}

En Guatemala, al gobierno municipal corresponde planificar y desarrollar acciones orientadas al desarrollo integral, la administración de los asuntos municipales, la prestación de servicios públicos, el ordenamiento territorial, el uso del suelo acorde con su vocación y dirigir las tendencias de crecimiento de los centros poblados y desarrollo urbanístico, esto se estipula en el Código Municipal, Decreto 122002. Todo ello a partir del mandato de ser eficaz, eficiente, basado en las políticas de descentralización, desconcentración y participación ciudadana.

En relación con el desarrollo, corresponde a la administración municipal instituir políticas locales en materia territorial, de servicios y atención a problemas ambientales. De manera específica, le compete la prestación de servicios públicos municipales como mercado, rastro, drenajes, agua potable, así como la recolección, tratamiento y disposición de desechos sólidos, de interés particular para el presente informe; la elaboración y mantenimiento del catastro municipal; la gestión ambiental de los recursos naturales renovables y no renovables del municipio (IARNA, 2009).

El municipio, por sus definiciones normativas, se cataloga como una entidad democrática y eso le da posibilidades de aportar a la gobernabilidad y la gestión ambiental, además sus autoridades son electas y el gobierno municipal está obligado a dinamizar los procesos de participación ciudadana en la formulación e institucionalización de las políticas públicas 
municipales, de los planes de desarrollo y en la formulación del presupuesto del municipio, priorizando necesidades y propuestas de solución (IARNA, 2006).

En esa dirección, también debe reconocer las formas de organización, participación y representación social, comunitaria e indígena, facilitar la información, participación ciudadana y la consulta, aspectos que están normados como derechos de vecindad y ciudadanía. Las alcaldías comunitarias se constituyen en un referente con representación y autoridad, además de ser la instancia que refleja la autoridad del gobierno municipal en la comunidad, lo que le confiere poder para aportar a las funciones establecidas para el municipio y su gobierno autónomo, en especial en la conservación, protección y desarrollo de los elementos de la naturaleza en su circunscripción territorial (Tchobanogloous et al., 1998).

Para la gestión ambiental local, los municipios cuentan con algunas condiciones (como la existencia de oficinas municipales de planificación y proyectos) y potencialidades (de participación, de diagnóstico, definición, planificación y ejecución) para definir políticas marco o agenda en esta materia.

Como fortaleza en el recurso financiero en Guatemala, las municipalidades cuentan con el $10 \%$ del presupuesto nacional repartido proporcionalmente; fondos del IVA-PAZ 1,5\% aproximadamente del impuesto del IVA ( $12,5 \%$ del $12 \%$ del total), las regalías sobre producción minera y petrolera existente en el municipio $(0,5 \%$ del total minero) ingresos por $\mathrm{Im}$ puesto único sobre inmuebles -IUSI- (IARNA, 2009).

En este sentido la gestión integrada de los residuos sólidos en la cabecera municipal, (Cobán, Alta Verapaz, Guatemala) como parte de la gestión ambiental local, también puede verse favorecida para lograr alcances de magnitudes beneficiosas para la población y la ciudad a medida que se le dé importancia y atención para obtener resultados que hasta ahora no se han alcanzado (IARNA, 2006).

La Unidad de Gestión Ambiental Municipal -UGAM- tiene la responsabilidad de encargarse de la gestión integrada para la administración de los residuos sólidos de Cobán, que desarrolle funciones de planificación, monitoreo, coordinación de los elementos que participan o que deben participar en este quehacer para lograr impactos beneficiosos en pro del bienestar ciudadano, principalmente en la reducción de la contaminación y como resultado el mejoramiento de la salud y el paisaje.

\subsection{Gestión Integral de Residuos Sólidos Urbanos (GIRSU)}

Según el MARN (2005), la Gestión Integral es un sistema de manejo de los Residuos Sólidos Urbanos -RSU- que, basado en el Desarrollo Sostenible, tiene como objetivo primordial la reducción de los residuos enviados a disposición final. Ello deriva en la preservación de la salud humana y la mejora de la calidad de vida de la población, así como también el cuidado del ambiente y la conservación de los recursos naturales.

El sistema GIRSU se impuso como el método adecuado para el manejo de los RSU luego de años de estudio, de numerosas experiencias realizadas en el mundo y del concurso de las ciencias exactas, médicas, naturales, sociales, económicas y el desarrollo tecnológico. Todos los estudios referidos a la Gestión Integral de RSU están dirigidos a disminuir los residuos generados -que son consecuencia inevitable de las actividades humanas- como medio idóneo para reducir sus impactos asociados y los costos de su manejo, a fin de minimizar los potenciales daños que causan al hombre y al ambiente.

\subsection{Gestión de residuos en Guatemala}

\section{- Generación de residuos sólidos domiciliares}

De acuerdo con el Perfil Ambiental de Guatemala (IARNA, 2006), en el país diariamente se generan residuos sólidos por un monto de entre 6.000 a 7.000 toneladas, de las cuales, el $54 \%$ se producen en las zonas urbanas y el restante $46 \%$ en las zonas rurales. La urbanización, con sus efectos sobre el medio ambiente, conlleva también hábitos de con- 
sumo y de actividades por parte de los individuos, lo que implica, impactos y consecuencias, dentro de los cuales destaca una creciente generación de residuos y desechos sólidos.

La generación de residuos sólidos domiciliares en centros urbanos sitúa a los departamentos de Guatemala (47,36 \%), Quetzaltenango (6,43\%) y Escuintla (4,80 \%) como los más importantes. En el ámbito rural, la generación es relativamente mayor en los departamentos de Huehuetenango, Alta Verapaz, San Marcos y Guatemala, entre ellos generan más del $36 \%$ del total producido en el área rural. El volumen total de los desechos que no es recolectado es de aproximadamente 11.010.638 toneladas anuales, siendo tal cantidad dispuesta en botaderos ilegales, quemada o enterrada. Esta cantidad representa el $65 \%$ de los desechos domiciliares generados en el país (IARNA, 2011).

\section{a) Destino final de los residuos sólidos}

Los residuos no recolectados se constituyen en uno de los grandes factores que ejercen presión al ambiente. La misma suele alimentar los botaderos ilegales tanto del área rural como urbana, y también existen hogares con el hábito de quemarla o enterrarla. Estos dos últimos fenómenos suceden con mayor frecuencia en el ámbito rural, en donde mayores extensiones de superficie y la dispersión de las viviendas refuerzan estas prácticas (Villanueva, 2008).

\section{b) Disposición de los residuos sólidos}

\section{- Áreas urbanas}

En el 2002 una mayor proporción de los hogares urbanos de Guatemala contaba con un servicio de recolección (58 \% frente al $47 \%$ de 1994), ya sea municipal o privado. El crecimiento del servicio municipal, de $11,5 \%$ a un $18.2 \%$ en el período es relevante, ya que manifiesta un aumento en el interés y la voluntad de las municipalidades por tomar medidas y ejercer un cierto control en el tema de los residuos. No obstante, permanece aún un número importante de hogares (459.892) que no cuenta con un servicio de recolección de desechos en el ámbito urbano (MARN, 2005).
Este esfuerzo, privado y municipal, por recolectar los residuos y desechos ha incidido positivamente en que los otros indicadores disminuyan: la proporción de hogares urbanos que quemaba los desechos en 1994 disminuyó de 21,6 \% a 19,9 \% en el 2002; el porcentaje de hogares que depositaban sus residuos en cualquier parte pasó de $20,7 \%$ a $12,6 \%$ en el mismo período; y solamente el $4,8 \%$ de los hogares enterraban sus desechos en el 2002. En el Perfil Ambiental de Guatemala de 2006 se indica que en 1994 ese índice alcanzaba el 7,3 \%. De acuerdo con el XI Censo de Población y VI de Habitación, el total de hogares urbanos asciende a 11.104.994 y existen aún 220.437 hogares que queman sus desechos y 138.679 que la tiran en cualquier parte (INE, 2002).

\section{- Áreas rurales}

La situación de las zonas rurales difiere grandemente de la observada en las zonas urbanas. Llama la atención, especialmente, el incremento en la proporción de hogares que queman los residuos. Este indicador pasó de 31,4 \% en 1994 a 41,4 \% en 2002, lo que significa que 454.051 hogares utilizan la práctica. Aunque se hicieron algunos esfuerzos incipientes en lo que respecta a dar un servicio de recolección en las áreas rurales, los mismos terminan siendo bastante insignificantes, ya que finalmente, en el 2002, el $95 \%$ de los hogares rurales no contaban con tal servicio (IARNA, 2006).

Según el Primer Informe sobre Desechos Sólidos Domiciliares, 2007, el 88,38 \% de los botaderos del país, no se encuentran autorizados y se pueden considerar clandestinos; el 11,62 \% se definen como de origen municipal, porque cuentan con autorización de la municipalidad únicamente y el $100 \%$ no tienen autorización por parte del MARN (no cuentan con Instrumento Ambiental aprobado).

\section{- Composición de los residuos sólidos}

En lo que respecta a la composición de los residuos y desechos sólidos domiciliares en el área metropolitana de Guatemala, el referente sigue siendo el estudio realizado por JICA (1995), en donde se concluye que del total de residuos el 63,3\% es materia orgánica, el 
$14 \%$ es papel y cartón, el 8,1 \% es plástico, el 3,6 \% es textil, 3,2\% es vidrio, el 3,0 \% es tierra y cenizas y el $5 \%$ restante se compone de madera, hojas, goma, metales, piedra, cerámica y pieles. Es importante destacar que un gran porcentaje son residuos que obviamente tienen potencial para ser reutilizados y reciclados. Según el Primer Informe sobre Desechos Sólidos Domiciliares, en el 2007 la distribución de la composición de los desechos sólidos en 80 municipios, la generación por estrato de los desechos orgánicos son el $44 \%$ de los desechos sólidos, en cuanto a los inorgánicos reciclables $41 \%$ (vidrio, caucho y plásticos; metales, papel y cartón) los demás porcentajes equivalen a suelo y otros (MARN, 2009).

\section{- Sistemas de manejo de residuos y desechos sólidos}

En la actualidad existen sistemas de tratamiento para los desechos sólidos; funcionan adecuadamente: por ejemplo la Planta del IRTRA en Retalhuleu y el Relleno Sanitario del kilómetro 22.5 en Villa Nueva. Los sistemas ubicados en Almolonga (Quetzaltenango) y San Antonio Aguas Calientes (Sacatepéquez) funcionan parcialmente, mientras que los ubicados en Flores y San Marcos no se utilizan (Mijangos, 2002).

\section{a) Problemática}

El acelerado crecimiento poblacional, la urbanización y los patrones de producción y consumo de la sociedad guatemalteca, han ocasionado como resultado un incremento en la generación de residuos sólidos y una particular composición de estos. Si bien parece ser un problema urgente de resolver y que preocupa a la mayoría de sectores (autoridades municipales, gobierno, iniciativa privada, sociedad civil, ONG), las acciones por abordar la problemática de manera integral, responsable y eficiente son escasas a nivel nacional; un ejemplo de ello es la existencia de apenas 10 sistemas de manejo de residuos sólidos al 2009, los cuales no operan en su totalidad (IARNA, 2010).

Los datos más recientes evidencian, no obstante, importantes mejoras en lo concerniente a la cobertura de recolección de residuos, particularmente en el área urbana. La recolección de los residuos sólidos se ve dificultada en el área rural por la alta dispersión de los poblados y comunidades y los hábitos culturales de quemar y enterrar la basura. Sin embargo, esta es únicamente una de las etapas del manejo integrado de los residuos sólidos. No existe ninguna experiencia, a nivel municipal, de una clasificación eficiente y sistematizada de los residuos, por lo que una propuesta proveniente de un estudio técnico y científico puede ser una alternativa importante para establecer un sistema de gestión integrada de los residuos sólidos.

En este sentido, se hace necesario que los gobiernos asuman acciones que permitan un manejo eficiente de los residuos y desechos a todo nivel, a la vez que se promueva una cultura que permita una mayor eficiencia en la utilización de las materias primas en los procesos industriales.

\section{b) Legislación y normativas}

En agosto de 2004, el Acuerdo Gubernativo 2342004 crea la Comisión Nacional para el Manejo de Desechos Sólidos ${ }^{1}$ _CONADES-, como la comisión encargada de coordinar y ejecutar las acciones técnicas y legales adecuadas en el manejo de desechos sólidos del país, derogando la antigua entidad CONADESCO. La CONADES es, por lo tanto, el órgano consultor y asesor en la formulación y dirección de las políticas nacionales de los desechos sólidos.

Uno de los grandes avances en lo que respecta al tema de los residuos sólidos es la aprobación, en abril del 2005, de la Política Nacional para el Manejo Integral de los Residuos y Desechos Sólidos, a través del Acuerdo Gubernativo 111-2005. Dicha política, concebida con una visión de diez años, establece una serie de acciones y programas que buscan alcanzar el eficiente manejo de los desechos sólidos en el país, y busca tener un impacto positivo en los ámbitos político-institucional, social, económico, ambiental y salud.

1 El Acuerdo Gubernativo 234-2004 habla sobre manejo de Desechos Sólidos, sin embargo, la presente tesis aborda el tema como Residuos Sólidos por la composición que tiene la basura con fines de reuso y reciclaje. 
Por otra parte, el Reglamento de Desechos Sólidos Hospitalarios, aprobado mediante el Acuerdo Gubernativo No. 509-2001, ha establecido ciertas medidas para motivar un manejo eficiente de los residuos hospitalarios en las distintas etapas del proceso, recolección, clasificación, almacenamiento, transporte, tratamiento y disposición final, con mayores o menores progresos en la eficiencia en los distintos hospitales y centros de salud, esencialmente en el área metropolitana. En el interior del país, el Reglamento ha sido poco aplicado (Recinos, 2014). En lo que respecta a las municipalidades que cuentan con un reglamento para manejo de desechos sólidos, en el 2000 el dato ascendía a 12. Para el 2004, CONADES consideró que el número oscilaba alrededor de 20; sin embargo, esta entidad considera que no más de tres municipalidades lo aplican. En este contexto, una de las grandes deficiencias en el tema de manejo de residuos sólidos es la falta de una ley marco que norme y establezca la obligatoriedad de contar con un reglamento para su manejo, lo que favorece que, en muchos casos, ante la ausencia de legislación que lo obligue, los alcaldes no asuman acciones en este tema (Recinos, 2004).

\subsection{Procedimientos para la evolución de Impacto Ambiental}

El Ministerio de Ambiente y Recursos Naturales, en base a la Ley de Protección y Mejoramiento de Ambiente, Decreto 68-86, en el artículo 8 establece que "Para todo proyecto, obra, industria o cualquier otra actividad que por sus características puede producir deterioro a los bienes y servicios ambientales renovables o no, al ambiente, o introducir modificaciones nocivas o notorias al paisaje y a los recursos culturales del patrimonio nacional", será necesario previamente a su desarrollo un Estudio de Evaluación de Impacto Ambiental, realizado por técnicos en la materia y aprobado por la Comisión del Medio Ambiente ${ }^{2}$. Además el Acuerdo Gubernativo 431-2007, "Reglamento de Evaluación, Control y Seguimiento Ambiental", establece los

2 La Comisión Nacional de Medio Ambiente desapareció para dar lugar al Ministerio de Ambiente y Recursos Naturales MARN. procedimientos para evaluar los Instrumentos Ambientales de todo proyecto (CALAS, 2007).

\subsection{Participación ciudadana como fundamento de la gestión ambiental}

Un eje fundamental de la gestión ambiental y la gobernabilidad local es la participación ciudadana en forma voluntaria y consciente. Es un derecho, pero también es una responsabilidad que se ejerce en el proceso de las políticas públicas en el nivel nacional, regional y local. Es, asimismo, una acción política que no garantiza per se resultados e impactos (MARN, 2009).

Aunque en los Acuerdos de Paz y el Código Municipal se norma y regula la participación ciudadana, existen factores que hacen que los procesos de participación estén cargados de múltiples debilidades, contradicciones, desencuentros, desarticulaciones; pero, también de fortalezas y posibilidades de aportes a la gestión ambiental sobre bases de gobernabilidad democrática (IARNA, 2009b).

En este sentido, la participación ciudadana que contribuiría a la gestión ambiental debiera caracterizarse por asumir la co-responsabilidad en la problemática ambiental, basada en una ética ambiental en donde se incorporen coherentemente los derechos específicos (como pueblos indígenas, por ejemplo) y los derechos universales (de la humanidad y de la Tierra), que prioricen los intereses colectivos y mayoritarios, antes que los particulares y minoritarios (CALAS, 2007).

Se debe cimentar en el conocimiento científico, experiencia y propuestas diversas, orientada a la protección, preservación, precautoriedad, mitigación, uso, regulación, control, monitoreo y evaluación de las acciones relacionadas con el ambiente y los elementos de la naturaleza, dirigida a lograr el desarrollo sostenible. En el proceso de maduración respecto de la responsabilidad en lo ambiental, el Estado de Guatemala ha pasado por un proceso en el cual desde leyes generales, hasta adquirir conciencia sobre que "la gestión integrada de los desechos y residuos sólidos en este país ha enfren- 
tado dificultades de ejecución y no ha solucionado los problemas que aquejan a los municipios. La calidad de desechos con las migraciones hacia las ciudades se ha vuelto negativa" (MARN, 2009:231).

Como se describe anteriormente esos residuos, en mayor cantidad de orgánicos biodegradables se incrementan en plásticos, hule, suelas, vidrio, ropa usada de tela nailon, envases de aluminio y otros metales, que necesitan que transcurra mucho tiempo para su degradación. En este sentido, la participación ciudadana es posible, siempre que se realice trabajo de orientación, educación y tratamiento de aspectos culturales, para poder enfrentar el problema de los residuos sólidos en el municipio de Cobán, ya que "está muy relacionada con la falta de cultura sobre el manejo integrado en nuestro estilo de vida, aunada una legislación inadecuada y ausencia de coordinación institucional" (MARN, 2009:2028).

Debido a que la participación ciudadana es fundamental en la gestión integrada de los residuos sólidos, la política marco busca "la participación e involucrar a todos los entes de la sociedad guatemalteca, haciendo conciencia que el manejo integrado de los desechos y residuos sólidos urbanos es el conjunto de procedimientos y estrategias que conforman el sistema de separación, recolección, transporte, tratamiento y disposición final y cuya meta es promover el establecimiento de una gestión integral que sea ambientalmente compatible y económicamente viable, así como la introducción de prácticas de producción más limpia incorporando la dimensión ambiental en su concepción y desarrollo" (Acdo Gub 111-2005). En Cobán, es precisamente eso lo que falta para completar las acciones que tiendan a manejar adecuadamente los residuos sólidos; una gestión integral tendiente a realizar una separación, recolección, transporte, tratamiento y disposición final, la cual puede empezar en los hogares.

\subsection{Gestión integrada de los residuos sólidos -GIRS-}

Dentro de la dinámica de la capacidad para la Gestión Ambiental Municipal -GAM- se puede observar la tipología municipal dentro de la Ges- tión Integrada de los Residuos Sólidos propuesta por la metodología del IARNA (2009), en la cual las relaciones del subsistema social e institucional, a través del subsistema productivo, relacionan la producción y el consumo con el subsistema ambiental a través de los residuos, dentro de los cuales se encuentran los residuos sólidos, enfoque de este estudio. En el mismo esquema se manifiesta la posibilidad del fortalecimiento de la capacidad de gestión ambiental con el requerimiento de la participación de la sociedad civil y el gobierno local, efectos que dependen de la capacidad social e institucional del municipio: la producción emite residuos y el consumo también.

En el caso de los servicios hospitalarios, el Ministerio de Salud Pública y Asistencia Social regula el tratamiento de los residuos hospitalarios a través del Código de Salud (Decreto 90-97); en la cabecera municipal de Cobán sí son tratados de acuerdo a las especificaciones, en los hospitales y clínicas privadas, los cuales son recolectados y procesados por empresas de la ciudad capital. Sin embargo, el total de la gestión integrada de los residuos sólidos producidos en Cobán, aún no se les da la atención debida, probablemente por falta de rubros destinados a esa actividad, pero lo que sí es seguro es que existe una débil GIRS en la ciudad y una alta contaminación por botaderos clandestinos, tiraderos en las calles y otros menores (Recinos, 2014). En tal sentido existe debilidad en la aplicación de la legislación existente, que de por sí es débil y escasa, a lo que se le suma la fragilidad institucional para gestionar recursos y hacer efectiva la utilización del presupuesto que manejan en las municipalidades. El concurso de la sociedad civil, es una opción para el mejoramiento de la GIRS en Cobán.

\subsection{Aprovechamiento y valoración como elemento funcional del sistema de GIRS}

El enfoque del GIRS no debe orientarse solamente a la construcción y operación de rellenos sanitarios, sino a identificar y utilizar sistemas de aprovechamiento y valorización de residuos, que 
permitan disminuir el espacio que estos rellenos ocupan. Hoy en día existen diversas alternativas técnicas y tecnológicas que permiten reducir su volumen, cantidad y modificar las características de peligrosidad, reduciéndolas o eliminándolas (Vargas, 2008).

Por otro lado, y con el fin de mejorar los balances energéticos de las ciudades y centros poblados, es necesario efectuar el reintegro al suelo de la mayor cantidad de fracciones orgánicas y nutrientes que fueron empleados para la generación de alimentos, los cuales diariamente se consumen. Estos alimentos se aprovechan de forma parcial y lo pertinente es que los residuos sean transformados y estabilizados de tal forma que puedan constituirse en nuevas formas utilizables para el suelo y su población biótica. De lo contrario, estos materiales depositados en rellenos sanitarios, se constituyen en una fracción inutilizable por el suelo y por los ecosistemas circundantes, constituyéndose en una fuente de contaminación por la producción de gases de efecto invernadero, especialmente metano $\left(\mathrm{CH}_{4}\right)$.

En algunos países se están implementando alternativas técnicas y tecnológicas así como normativas, tanto en los procesos productivos como en procesos de separación, aprovechamiento y valorización de residuos, encaminadas hacia el concepto de "Cultura de la No Basura", la cual busca minimizar o reducir la generación de los residuos sólidos domésticos en el lugar de origen, retornando entre otras medidas a la utilización de en- vases y empaques degradables. Este es un compromiso no solamente de la comunidad, sino de la industria y el comercio de bienes de consumo (ICONTEC, 2009).

De acuerdo con la Política de Gestión Integral de Residuos Sólidos en otras realidades, el aprovechamiento se entiende como el conjunto de fases sucesivas de un proceso, cuando la materia inicial es un residuo, entendiéndose que el procesamiento tiene el objetivo económico de valorizar el residuo u obtener un producto o subproducto utilizable y aprovechable, son aquellos residuos que pueden ser reutilizados o transformados en otro producto, reincorporándose al ciclo económico y con valor comercial.

La maximización del aprovechamiento y valorización de los residuos generados y en consecuencia la minimización de las cantidades, contribuye a conservar y reducir la demanda de recursos naturales, disminuir el consumo de energía, preservar los sitios de disposición final y reducir sus costos, así como a reducir la contaminación ambiental al disminuir la cantidad de residuos que van a los sitios de disposición final o que simplemente son dispuestos en cualquier sitio contaminando el ambiente. El aprovechamiento y valorización debe realizarse siempre y cuando sea económicamente viable, técnicamente factible y ambientalmente conveniente. El aprovechamiento de los residuos sólidos tiene como fin último su incorporación al ciclo económico productivo (Villanueva, 2008). 


\section{Ubicación del área de estudio}

Figura 1

Mapa de ubicación del municipio de Cobán, y su área urbana en

el contexto de Centro América

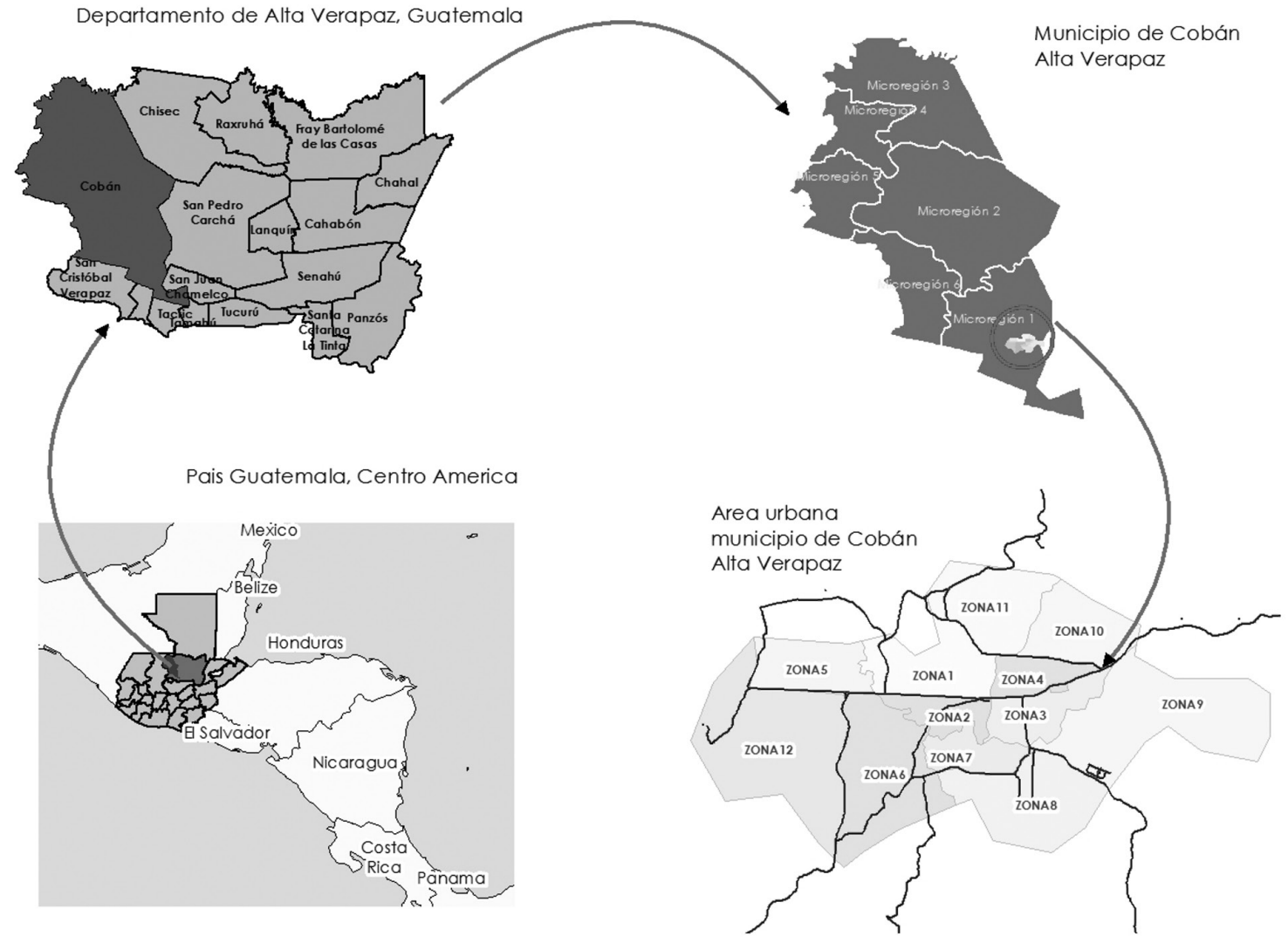

Fuente: Base Cartográfica del IGN e INE, Municipalidad de Cobán, y datos tomados en campo Elaboración: MSc. Gustavo García

Programa de Doctorado: Ciencias Naturales para el Desarrollo con énfasis en gestión y cultura ambiental UNED, ITCR, UNA. 
Figura 2

Mapa de ubicación del botadero municipal en el área urbana de Cobán, Alta Verapaz

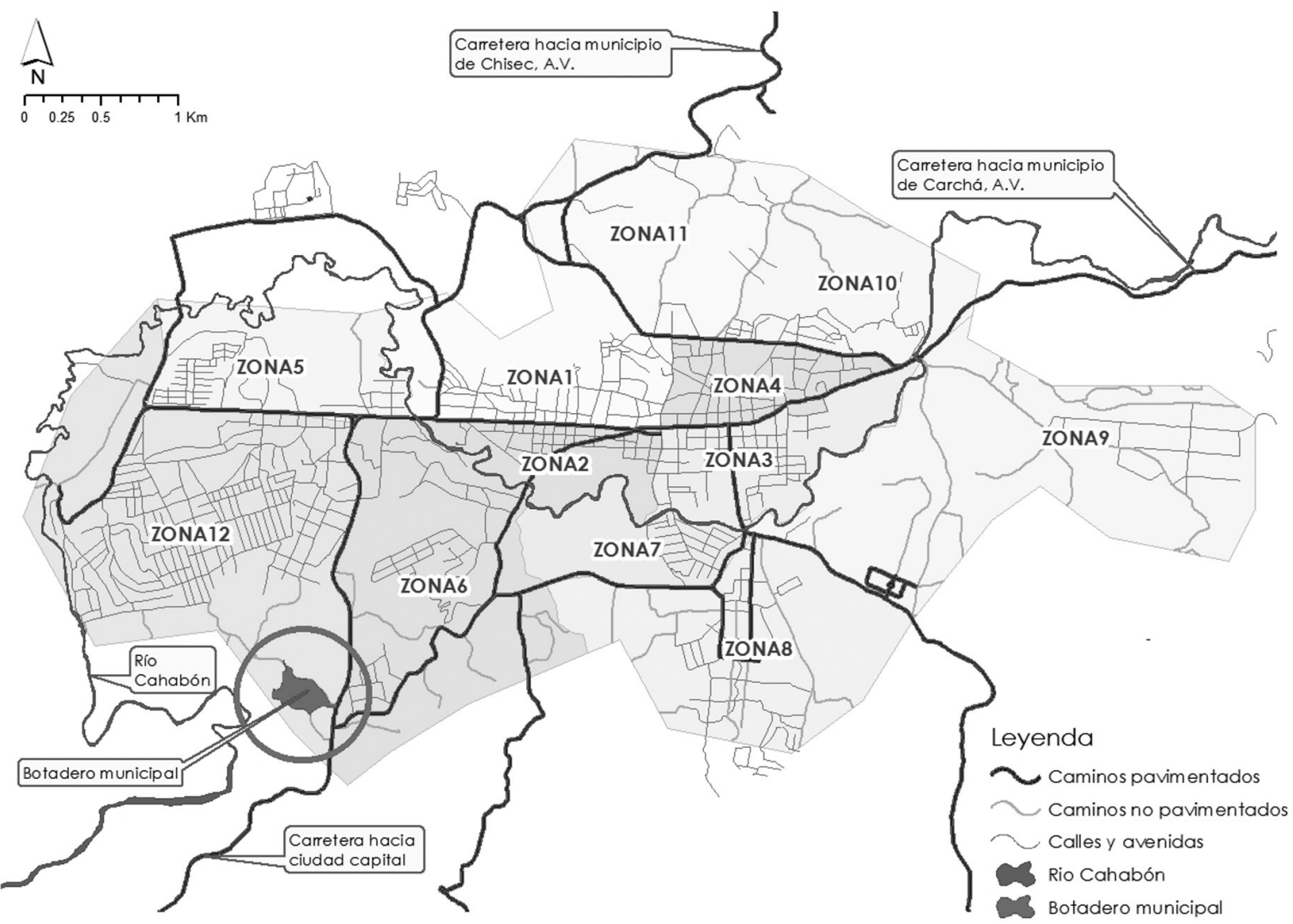

Fuente: Base Cartográfica del IGN e INE, Municipalidad de Cobán, y datos tomados en campo Elaboración: MSc. Gustavo García

Programa de Doctorado: Ciencias Naturales para el Desarrollo con énfasis en gestión y cultura ambiental UNED, ITCR, UNA.

\section{Resultados y discusión}

La información obtenida al emplear los instrumentos para establecer la gestión de los residuos sólidos en Cobán fue recolectada a partir de tres bole- tas de encuesta, aplicadas a personas particulares, empleados municipales y empresas recolectoras de RS con base en los indicadores GIRS de la metodología del IARNA como se muestra en la Tabla 1: 
Tabla 1

Resultados globales obtenidos de la aplicación del instrumento utilizado para establecer la gestión de los residuos sólidos en el municipio de Cobán

\begin{tabular}{|c|c|c|c|c|}
\hline \multirow{2}{*}{$\begin{array}{l}\text { Elementos } \\
\text { de la gestión } \\
\text { municipal }\end{array}$} & \multirow{2}{*}{$\begin{array}{l}\text { Criterios de medición } \\
\text { (Áreas de GIRS) }\end{array}$} & \multirow{2}{*}{ Indicadores GIRS } & \multicolumn{2}{|c|}{ Resultados } \\
\hline & & & Puntos & Porcentaje \\
\hline \multirow{4}{*}{$\begin{array}{l}\text { Bases técnico } \\
\text { científicas para } \\
\text { la gestión. }\end{array}$} & $\begin{array}{l}\text { Capacidad de prestación } \\
\text { del servicio de recolección } \\
\text { de RS. }\end{array}$ & $\begin{array}{l}\text { Registro actualizado de botaderos no } \\
\text { autorizados en el municipio. }\end{array}$ & 0 & No \\
\hline & Tipo de disposición final. & Disposición de los residuos recolectados. & 4 & $60 \%$ basurero \\
\hline & \multirow{2}{*}{ Recuperación de residuos } & $\begin{array}{l}\text { Porcentaje de basura orgánica aprove- } \\
\text { chada. }\end{array}$ & 0 & $0,0004 \%$ \\
\hline & & $\begin{array}{l}\text { Porcentaje de basura inorgánica aprove- } \\
\text { chada. }\end{array}$ & 0 & $0,0012 \%$ \\
\hline \multirow{2}{*}{$\begin{array}{l}\text { Políticas y } \\
\text { estrategias } \\
\text { públicas } \\
\text { explícitas. }\end{array}$} & $\begin{array}{l}\text { Capacidad de normar el } \\
\text { aseo del municipio. }\end{array}$ & $\begin{array}{l}\text { Un reglamento municipal para la } \\
\text { recolección, el transporte, tratamiento y } \\
\text { disposición final de los RS. }\end{array}$ & 0 & No \\
\hline & $\begin{array}{l}\text { Cobertura de barrido de } \\
\text { calles. }\end{array}$ & $\begin{array}{l}\text { Longitud de calles urbanas que reciben } \\
\text { servicio de barrido. }\end{array}$ & Bajo & $30 \%$ \\
\hline \multirow{9}{*}{$\begin{array}{l}\text { Estructura } \\
\text { institucional, } \\
\text { liderazgo } \\
\text { y recursos } \\
\text { financieros. }\end{array}$} & $\begin{array}{l}\text { Capacidad de prestación } \\
\text { del servicio de recolección. }\end{array}$ & $\begin{array}{l}\text { Porcentaje de habitantes atendidos por } \\
\text { el servicio de recolección de residuos. }\end{array}$ & Medio & $60 \%$ (privado) \\
\hline & $\begin{array}{l}\text { Capacidad de normar el } \\
\text { aseo del municipio. }\end{array}$ & $\begin{array}{l}\text { Una instancia encargada de los residuos } \\
\text { domésticos y no domésticos }\end{array}$ & 0 & No \\
\hline & \multirow{2}{*}{$\begin{array}{l}\text { Capacidad del personal } \\
\text { (preparación) }\end{array}$} & $\begin{array}{l}\text { Aprovisionamiento del material y aten- } \\
\text { ción médica al personal }\end{array}$ & 0 & No \\
\hline & & $\begin{array}{l}\text { Capacitaciones sobre MIRS para el per- } \\
\text { sonal a cargo de saneamiento. }\end{array}$ & 0 & No \\
\hline & \multirow[b]{2}{*}{$\begin{array}{l}\text { Cobertura de recolección } \\
\text { a nivel urbano. }\end{array}$} & $\begin{array}{l}\text { Porcentaje de población urbana atendi- } \\
\text { da por el servicio de recolección. }\end{array}$ & Privado & $60 \%$ \\
\hline & & $\begin{array}{l}\text { Total de toneladas anuales de residuos } \\
\text { municipales recolectados en el área ur- } \\
\text { bana y depositada en un relleno (basu- } \\
\text { rero, etc.) }\end{array}$ & Privado & $\begin{array}{c}5243 \\
(60 \% \text { gente) }\end{array}$ \\
\hline & Costo de recolección. & Costo real de tren de aseo por vivienda. & Privado & US\$4.00 \\
\hline & Costo de disposición final. & $\begin{array}{l}\text { Costo por tonelada de residuos dispues- } \\
\text { tos vs. asignación presupuestaria. }\end{array}$ & $\begin{array}{l}\text { No } \\
\text { aplica }\end{array}$ & 0.00 \\
\hline & $\begin{array}{l}\text { Capacidad de recupera- } \\
\text { ción de costos. }\end{array}$ & $\begin{array}{l}\text { Nivel de subsidio municipal anual a la } \\
\text { prestación del servicio de MRS. }\end{array}$ & Nada & 0.00 \\
\hline \multirow{3}{*}{$\begin{array}{l}\text { Respaldo so- } \\
\text { cial y empre- } \\
\text { sarial. }\end{array}$} & $\begin{array}{l}\text { Capacidad de recupera- } \\
\text { ción de costos. }\end{array}$ & $\begin{array}{l}\text { Mora en pago por recolección de } \\
\text { basura. }\end{array}$ & Medio & $20 \%$ \\
\hline & \multirow{2}{*}{$\begin{array}{l}\text { Participación social en ac- } \\
\text { tividades relacionadas. }\end{array}$} & $\begin{array}{l}\text { Porcentaje de las viviendas que clasifi- } \\
\text { can la basura. }\end{array}$ & Ínfima & $0.0004 \%$ \\
\hline & & $\begin{array}{l}\text { Número de actividades por año de par- } \\
\text { ticipación pública para gestión de los RS }\end{array}$ & 0 & 0 \\
\hline
\end{tabular}

Fuente: Datos de campo, 2013 basado en metodología del IARNA, 2011. 
Al analizar los resultados obtenidos y descritos en la Tabla 1, se puede observar que la municipalidad de Cobán está débil en bases técnicas para la prestación del servicio de recolección sin registro de tiraderos de residuos y sin capacidad para la recuperación de los residuos sólidos, sean orgánicos o inorgánicos.

Existe dentro del perímetro del área que ocupa el vertedero a cielo abierto y sin manejo de Sachamach, un grupo de familias dedicadas a la recolección y clasificación de materiales como metales, plásticos, hules, papel y cartón que todavía pueden venderse como chatarra o para cualquier uso artesanal; son familias que sobreviven de esa actividad y cuyos ingresos son muy bajos a raíz de esa actividad y sin regulaciones por parte de la municipalidad para realizar su actividad.

De la gestión municipal para el manejo de RS sólo se tiene el área donada para el vertedero, al cual puede asistir cualquier persona particular con capacidad para transportar sus RS o las empresas recolectoras, que también son privadas y que solamente tienen la obligación de registrarse en la municipalidad y cobran a las personas que soliciten el servicio.

Sólo 4 de cada 10.000 personas en Cobán, clasifican los residuos sólidos para entregarlos a las empresas recolectoras y 12 de cada 10.000 procesan los residuos orgánicos para convertirlos en abono, sea porque la clasifiquen o no, de acuerdo a los datos colectados de las boletas y según las muestras tomadas en los hogares.

De las políticas y estrategias públicas establecidas en la municipalidad, sólo se cubre un bajo porcentaje de las calles de la ciudad en las cuales se practica el barrido y recolección, dentro de la misma actividad, también se recolectan los residuos de los botaderos no registrados. Esta actividad cubre solamente el $30 \%$ de las calles urbanas, equivalente a las cuatro zonas, pero en las calles y avenidas del centro de la ciudad.

Un $40 \%$ de las familias de Cobán, tiran los residuos a las orillas de las calles de lugares apartados, ríos, fosas naturales y otra parte la entierra o la incinera.
El resultado de esta actividad genera contaminación por gases como $\mathrm{CO}, \mathrm{CO}_{2}, \mathrm{O}_{3}$ y otros que producen daños a la salud, incluyendo la incineración del forro de conductores de cobre y otros metales para limpiarlos y poderlos comercializar en las llamadas recicladoras de todo tipo de material, las cuales componen el 0,00012 \% del total de población.

En cuanto a la variable estructura institucional, liderazgo y recursos financieros, no existe una instancia encargada de los residuos sólidos domésticos y no domésticos y, por lo mismo no tiene personal para el efecto; las personas que administran las escasas actividades privadas y municipales para la GIRS, son empleados cuya función principal es otra, no como la oficina municipal del agua y drenajes o Catastro.

Por lo antes descrito, cabe indicar que, la cobertura de hogares solo alcanza el 60 \% de Cobán y son los que tienen la capacidad económica para costear el servicio, el cual tampoco se hace en forma adecuada ya que el personal que labora no tiene capacitaciones para esa actividad, servicio médico, ni equipo y herramientas apropiadas para su protección en cuanto a seguridad física y atención médica.

El transporte de los RS consiste en camiones comunes, descubiertos tanto de la parte de arriba como posterior del depósito de carga (carrocería), convirtiéndose en un medio inadecuado para tal servicio. El resultado de usar esos medios de transporte es que varias bolsas con basura se queden tiradas en la ruta hacia el vertedero y se conviertan en contaminadores del paisaje y de las calles por donde circulan.

La cantidad de residuos sólidos recolectada y depositada en el vertedero de Sachamach es de 5.243 toneladas al año y constituye el $60 \%$ de los RS generados en la ciudad de Cobán. El costo de la recolección de los desechos por vivienda es de unos US\$48,00 anuales, los cuales no los pueden pagar todas las familias.

En lo referido a la variable respaldo social e institucional, la municipalidad de Cobán recibe apoyo institucional a través de las empresas recolectoras de RS, que además son contribuyentes al pagar sus arbitrios por el permiso para realizar tal actividad. 
Sin embargo, se ha determinado que un promedio del $20 \%$ de los usuarios del servicio de recolección de RS de Cobán, se mantiene en mora en el pago de sus cuotas mensuales, situación que no apoya a las empresas para realizar su trabajo de manera integral. El porcentaje de personas que reciclan y procesan residuos sólidos en Cobán, no es determinante, se considera nulo.

El sistema de gestión de los residuos sólidos en Cobán fue realizado por la municipalidad hasta inicios de 1980; sin embargo, por lo oneroso que le resultaba a la municipalidad y el costo por vivienda (menor de US\$1,00) se dejó de prestar el servicio en las zonas 1, 2, 3 y 4 que era el área que atendía, esto se debió a la falta de fondos para el efecto, por lo cual se le cedió a empresas privadas el derecho para prestar ese servicio (Municipalidad de Cobán, Oficina de Registro y Control).

En la actualidad, la municipalidad todavía se encarga de recolectar los residuos sólidos generados en lugares públicos como calles, mercados y parques. No obstante, el manejo de los RS comprende un proceso de colección en casas, áreas comerciales, mercados públicos e instalaciones industriales, sitios de almacenamiento temporal y transporte al vertedero municipal. Este proceso no incluye medidas administrativas, reglamentarias, manejo integrado, campañas de educación a la población y empresarios para un adecuado manejo; entonces, la GIRS en la ciudad de Cobán es deficiente.

Si no se dispone de fondos para realizar una gestión integral, debería por lo menos existir una entidad, dependencia municipal que se encargue de mejorar el sistema de GIRS, en la cual se pueda involucrar a las instituciones educativas, de extensión y servicios para colaborar con el sistema. Esta dependencia municipal muy bien puede ser la UGAM, es decir la Unidad de Gestión Ambiental Municipal.

Se estima que de los factores que influyen en las personas que no contratan los servicios de recolección son el nivel económico de las familias, el nivel educativo de las personas y el desconocimiento de los daños que produce al ambiente los RS y algu- nos métodos de tratamiento como la incineración y la descomposición en sitios muy húmedos. Ello obedece a la pobreza y al índice de desarrollo humano de los sectores más pobres; en la región a la que pertenece Cobán es de 0,48 (PNUD, 2009).

\section{- Percepción de las personas acerca de la GIRS}

De las respuestas dadas por las personas a la pregunta de opinión, un 45,8 \% ven a los desechos sólidos municipales como un problema de contaminación ambiental, mientras que el $92 \%$ de los encuestados identifican a la carencia de una gestión integrada de los residuos sólidos en la ciudad de Cobán y agregan que debe ser institucionalizada, ya que las compañías privadas prestan un servicio deficiente, argumentando que su meta es lucrativa y no con el fin de mejorar el ambiente.

En cuanto al efecto más negativo en el que influye el deficiente manejo de los RS el $66 \%$ de los pobladores indicó que es sobre la salud de las personas, $24 \%$ en la contaminación del aire y 10 por ciento efectos visuales. Los resultados se muestran en el Cuadro 1:

\section{Cuadro 1}

Resumen de la opinión de los habitantes de la ciudad de Cobán acerca del efecto negativo del deficiente manejo de Residuos Sólidos

\begin{tabular}{|c|c|c|}
\hline No & Opinión & Porcentaje \\
\hline & $\begin{array}{l}\text { La salud: efecto más negativo } \\
\text { de RS }\end{array}$ & 66,0 \\
\hline & Contaminación del aire & 24,0 \\
\hline & Efectos visuales & 10,0 \\
\hline
\end{tabular}

Fuente: Datos de campo, año 2013.

En lo referente a los indicadores socioambientales del municipio de Cobán, Alta Verapaz, cabe indicar que posee una dimensión ambiental con un peso de 2,2, una dimensión económica de 2,5, una dimensión institucional de 2,5 y una dimensión social de 2,5 con una sumatoria de 9,7 , que es inferior al estándar establecido que es de 10,0. 
- El desempeño municipal de Cobán en la gestión ambiental

De acuerdo con la metodología implementada en la presente investigación y según las variables consideradas en el área de análisis, se debe iniciar con el sector de respaldo institucional donde se puede resaltar que la sumatoria total obtenida es 19/25, lo cual corresponde a un $76 \%$. Esto significa que se cuenta en Cobán con apoyo por parte de las autoridades municipales en la GIRS, observando que los datos más bajos pueden situarse en la capacidad de prestación de los servicios de recolección y la población que cuenta con dicho servicio y el registro de botaderos clandestinos, que hacen un total de 22. Los resultados se muestran en la Tabla 2:

Tabla 2

Indicadores GIRS de Cobán, Alta Verapaz, Guatemala

Área de análisis 1: Respaldo institucional

\begin{tabular}{|c|c|c|c|c|c|}
\hline & \multirow{2}{*}{ Variables } & \multirow{2}{*}{ No. } & \multirow{2}{*}{ Indicadores } & \multicolumn{2}{|c|}{ Puntaje } \\
\hline & & & & Asignado & Obtenido \\
\hline \multirow[t]{2}{*}{1.1} & \multirow{2}{*}{$\begin{array}{l}\text { Capacidad de prestación } \\
\text { del servicio de recolección }\end{array}$} & 1 & $\begin{array}{l}\text { Población con servicio de recolección de basura } \\
\text { (catastro) }\end{array}$ & 5 & 3 \\
\hline & & 2 & Registro actualizado de botaderos ilegales & 4 & 4 \\
\hline \multirow{2}{*}{\multicolumn{2}{|c|}{$\begin{array}{l}1.2 \text { Capacidad de normar el } \\
\text { aseo del municipio }\end{array}$}} & 3 & Aplicación de una ordenanza de aseo o similar & 5 & 5 \\
\hline & & 4 & Unidad de saneamiento municipal o mancomunada & 3 & 2 \\
\hline & \multirow{2}{*}{$\begin{array}{l}\text { Capacidad del personal } \\
\text { (preparación) }\end{array}$} & 5 & $\begin{array}{l}\text { Aprovisionamiento de material y atención médica al } \\
\text { personal }\end{array}$ & 3 & 2 \\
\hline & & 6 & $\begin{array}{l}\text { Capacitaciones sobre MIRS para el personal a cargo } \\
\text { de saneamiento }\end{array}$ & 6 & 3 \\
\hline & & & Total de respaldo institucional & 26 & 19 \\
\hline
\end{tabular}

Fuente: Elaboración propia en base al IARNA, 2011

Se puede observar que el personal posee pocos conocimientos en relación con el manejo integral de los RS, con lo cual debe incrementarse los valores y principios ambientales conjuntamente con las autoridades encargadas del sector institucional. Para tener una mejor interpretación y visualizar de mejor manera el comportamiento de las variables analizadas se ha elaborado un modelo que se muestra en la Gráfica 1:

\section{Gráfica 1 \\ Modelación gráfica del respaldo institucional sobre la GIRS en Cobán}

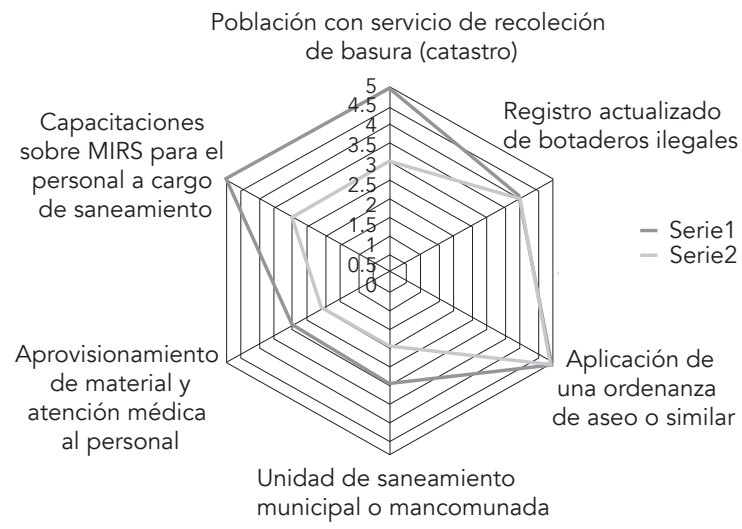

Fuente: Datos de campo 
La gráfica 1 modeliza el comportamiento de las variables evaluadas. La serie 1 que corresponde a la ponderación asignada y la serie 2 a la ponderación obtenida. Se puede observar que respecto al registro actualizado de botaderos ilegales, existe un número indicador de 4 y un número obtenido también de 4, esto explica que dicho registro cumple con el número mínimo o asignado dentro de la GIRS, lo cual no necesariamente significa que esté del todo bien, ya que para que cumpla de manera óptima para la búsqueda de la gestión de los residuos sólidos debería alcanzar el número total de 5 , sin embargo, dicho número al estar igual con el asignado manifiesta que hay indicios positivos en su búsqueda.

En relación con el servicio de recolección de basura (catastro), se obtuvo una calificación del indicador de 3 con una diferencia de 2 en relación al asignado, con lo cual se denota que la GIRS, en este renglón, está deficiente debido a que dicha diferencia es un $20 \%$ para poder gestionar los residuos sólidos, en cuanto al establecimiento de un sistema adecuado para la recolección de residuos sólidos, que faciliten tanto su colecta como su disposición hacia el relleno sanitario, en el cual se hizo el levantamiento y cuantificación de basura.

La mayoría de los indicadores correspondientes al área de análisis de respaldo institucional, presenta una brecha entre lo asignado y lo obtenido y lo ideal, lo cual remarca de manera significativa la falta de gestión de los residuos sólidos en el municipio de Cobán.

No obstante hay otros factores que inciden en la GIRS, por lo que otra área de análisis fue la eficacia de recolección de los residuos sólidos en Cobán. Los resultados obtenidos se presentan en la Tabla 3:

Tabla 3

Eficacia en la recolección de los residuos sólidos en Cobán

Variables
No.

7 Porcentaje de la población atendida

8 Proporción de residuos recolectados al mes

9 Porcentaje de población atendida

10 Proporción de residuos recolectados al mes

Kilómetros que reciben servicio de barrido de calles

11 Kilóme

2.3 Cobertura de barrido de calles
Indicadores
2.1 Cobertura de recolección a nivel urbano

2.2 Cobertura de recolección a nivel rural

12 Kilómetros que reciben servicio de limpieza en las

\section{Puntaje}

Asignado Obtenido

6

5 calles rurales

$4 \quad 3$

5

1

3

1

5

4

1

$2 \quad 1$

Total de respaldo institucional

25

Fuente: Elaboración propia en base al IARNA, 2011

En relación con la eficacia en la recolección de los RS, se puede observar que la prestación de dicho servicio es regularmente eficiente en el área urbana, no así en área periférica y rural, lo que hace una proporción baja de 15/25. La Gráfica 2 ilustra de mejor manera el comportamiento de la recolección de los residuos sólidos en Cobán: 


\section{Gráfica 2 \\ Modelación gráfica de la recolección de los residuos sólidos en Cobán}

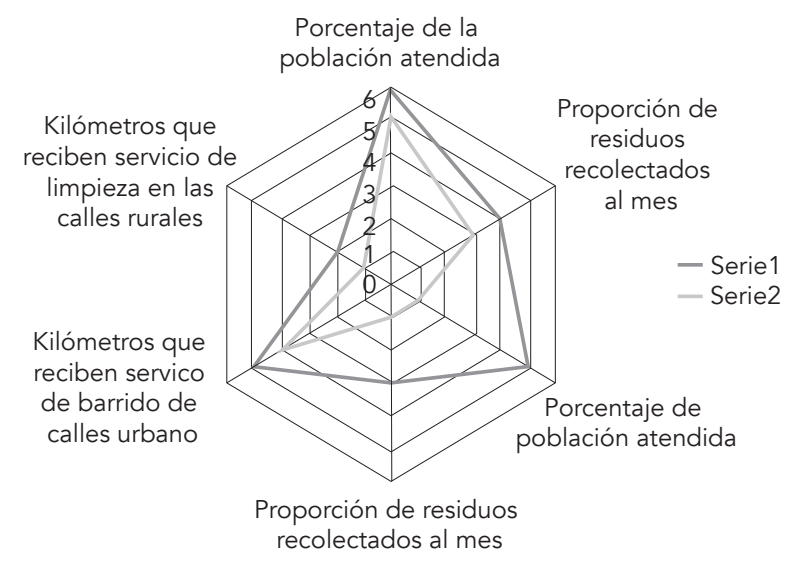

Fuente: Elaboración propia en base al IARNA, 2011

La Gráfica 2 describe el comportamiento del servicio y la extensión de la cobertura en cuanto a la limpieza de las calles, la población atendida, y la proporción de los residuos recolectados al mes, en la cual se pone en comparación el área urbana y el área periférica o rural.

Lo anterior es muy discutible ya que al ser un servicio proporcionado por empresas privadas, no cubre la suficiente extensión del área urbana del municipio de Cobán, lo cual tiene una incidencia directa en la acumulación y el promontorio de botaderos clandestinos, lo cual incrementa la contaminación y polución en el área de estudio. Por ejemplo, tal y como se observa en cuanto a la ponderación asignada en relación al porcentaje de la población atendida en el área urbana, se puede observar que su valor es de 6, y el obtenido es de 5, lo cual deja una diferencia de lo óptimo de 1 punto, si se compara con el área rural, se puede notar en este modelo gráfico que la ponderación asignada es de 2, un gran contraste con el área rural. Respecto al punteo asignado, existe una diferencia de puntuación de 3 puntos entre el área rural y 4 con lo óptimo y/o asignado, y esto refuerza la hipótesis planteada, en el sentido de que no existen indicios que busquen la gestión de los residuos sólidos en el municipio de Cobán, debido a que si bien se presta el servicio, este no presenta un indicio de mejorar la cobertura, en el área periférica y en el área rural, aunque en el mediano plazo, se pueda gestionar, en el área urbana.

Es evidente que el servicio municipal de recolección de RS, por parte de la municipalidad es inexistente, y existe un monopolio de únicamente dos empresas, lo cual dificulta la recolección, traslado, disposición y tratamiento de los mismos.

A pesar de existir una mayor presión social por parte de la población para que las autoridades municipales, sean más eficientes en este servicio, hasta el momento ha resultado ineficaz, considerando que anualmente se cobra un arbitrio municipal, que está en proporción del ingreso que percibe el vecino, y que no se ve reflejado en su utilización para su uso en el "ornato" de la ciudad, considerando que el municipio en estudio se constituye como un sector de amplia demanda del turismo nacional e internacional.

Por consiguiente es imperante despertar un liderazgo institucional capacitado para propiciar la gestión de los residuos sólidos, por lo que no es necesario esperar que instituciones externas como organizaciones no gubernamentales o institucionales realicen el diseño y financiamiento de un proyecto civil de alto impacto, para mejorar las condiciones de vida de la población.

Para ello, y en beneficio del mejoramiento continuo y sostenible que beneficie y tenga incidencia en las actitudes, valores, comportamiento y cultura ambiental de los cobaneros se debe considerar:

- La actualización y desarrollo de un plan de acción con plena participación social, considerando la cosmogonía propia del área de estudio que es netamente de etnia Q'eqchí, una con la población más alta de Guatemala, pero que ha carecido de un programa de educación ambiental dirigido a su cultura, sus costumbres, tradiciones y formas de vida, que chocan, con el simple, traslado, recolección y transporte de RS.

- Es de urgencia la implementación de un sistema de RS, contrario al inexistente, ya que redunda aún más sobre la contaminación socioambien- 
tal. Para ello se debe incluir la calidad del servicio de recolección, la cobertura, el manejo controlado del botadero municipal, el fortalecimiento institucional y el manejo financiero con alta probidad debido a cobro de tarifas, y arbitrios ya existentes por parte de las autoridades, como es el caso del boleto de ornato anual, que pagan todos los vecinos de la localidad, y que no se refleja directamente en la inversión social, ecológica y ambiental para el manejo y la GIRS.

- Es importante considerar el ordenamiento y gerencia de recursos para inversiones necesarios, como la adquisición de terrenos y la construcción de un verdadero relleno sanitario, con todas las características técnicas y de tratamiento, debido a que el crecimiento poblacional así lo amerita.

- Con todo lo anterior podemos deducir, tanto al observar la figura respectiva, como la tabla enunciada, que no existe eficacia en la recolección de los residuos sólidos, en el área de estudio, por lo que es imperante la implementación de todo un sistema integral de gestión de los RS.

Para continuar con el análisis del desempeño municipal es necesario abordar la eficiencia financiera, por lo que de acuerdo con la metodología del IARNA, 2011 los resultados en esta área de análisis se presentan en la Tabla 4:

Tabla 4

Eficacia financiera en la GIRS de Cobán, Alta Verapaz

Variables

No.

Indicadores
Puntaje

Asignado Obtenido
3.1 Costo de recolección

3.2 Costo de disposición final

3.3 Capacidad de recuperación de costos
13 Costo del servicio de tren de aseo por vivienda vrs. Asignación

Costo por tonelada de residuos dispuestos vrs. Asignación

Generación anual de ingresos vrs. costo total del servicio

16 Costo de recolección y disposición vrs. asignación presupuestaria

17 Mora en pago por recolección de basura

Total de respaldo institucional
5

4

5

4

5

$5 \quad 3$

5 1

25

Fuente: Elaboración propia en base al IARNA, 2011

Con relación al tema de la eficiencia financiera con relación a la GIRS, se puede denotar, que el costo de recolección es relativamente alto, en comparación a que no se efectúa ningún tipo de tratamiento a los RS, con lo cual se fortalece la hipótesis en el sentido de que no hay ninguna gestión integrada de los residuos sólidos, eficiente, ni las mínimas intenciones de implementarla.

Es por ello que el costo de implementación, operación, mantenimiento y administración gerencial de la
GIRS, debe ser eficiente, al alcance de los recursos de la población y económicamente sostenible, con ingresos técnicamente calculados para cubrir de manera eficaz el servicio. Para tener una mejor idea del comportamiento de la eficacia financiera se ha elaborado la Gráfica 3 para demostrar que no existen aspectos organizativos, lo cual limita que la GIRS no sea simple y dinámica, sino al contrario cuasi nula, inoperante y compleja, por la falta de visión de los diferentes actores sociales del área de estudio. 


\section{Gráfica 3}

Modelación gráfica de eficiencia financiera de las GIRS en Cobán

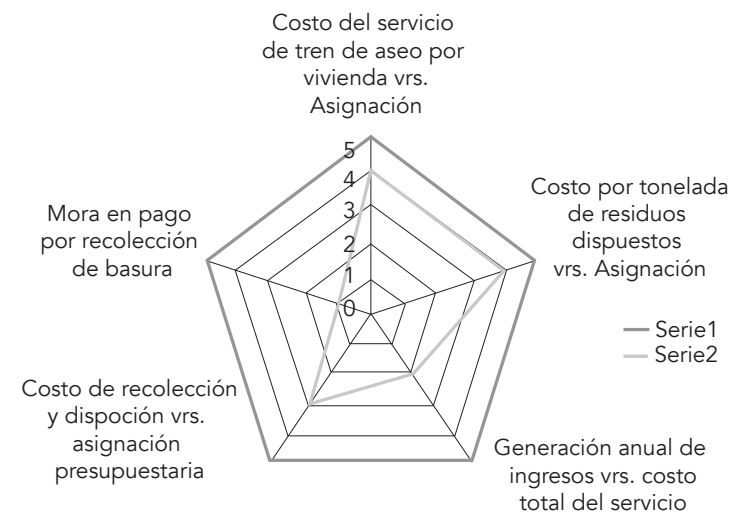

Fuente: Elaboración propia en base al IARNA, 2011

Como se puede observar, es perceptible la deficiencia financiera de la recolección de los RS. Al analizar los indicadores que conforman esta área de estudio, en relación a la ponderación alcanzada tanto en lo obtenido como en lo asignado existe mucha diferencia entre cada una de las variables, para alcanzar el óptimo deseado que fomente la GIRS.

En relación con el costo del servicio del tren de aseo por vivienda versus la asignación financiera munici- pal, se observa que lo ideal sería una puntuación de 5 y en la presente investigación de acuerdo a la validación de la metodología de IARNA, se alcanzó un punteo de 4, probablemente la diferencia no sea muy alta, sin embargo, en términos de gestión, es quizá un aspecto que se pueda alcanzar a mediano plazo, siempre y cuando se implementen estrategias de GIRS, de lo contrario, permanecerá tal y como se ha venido comportando durante los últimos diez años. La capacidad de recuperación de lo invertido por la recolección de RS, es bastante baja, al ver lo asignado, alcanza una puntuación de 5, y lo obtenido es de 1, lo cual refleja, una gran ineficacia financiera. Esto no hace sostenible el sistema de aseo o recolección de RS en Cobán. Por consiguiente, limita y dificulta cualquier iniciativa, que pueda presentar las autoridades municipales que fomenten los valores y principios pro ambientales de la población, en el sentido de que es muy reducida la captación de recursos, para dicha actividad.

Finalmente, para analizar el desempeño municipal es necesario considerar el manejo del impacto ambiental, por lo que en la Tabla 5 se presentan los resultados obtenidos según los indicadores estudiados.

Tabla 5

Manejo del impacto ambiental en la GIRS de Cobán, Alta Verapaz

Variables
No.

18 Tipo de lugar donde se disponen los residuos recolectados

19 Porcentaje de las viviendas que clasifican la basura

20 Número de actividades / año para cambiar actitudes

21 Porcentaje de basura orgánica aprovechado
Indicadores

Puntaje
4.1 Tipo de disposición

4.2 Participación social en actividades relacionadas

4.3 Recuperación de residuos
22 Porcentaje de basura inorgánica aprovechado

Total de respaldo institucional

Asignado Obtenido

9

4

4

4

4

25
7

2

2

1

Fuente: Elaboración propia en base al IARNA, 2011

Como se puede observar en la Tabla 5 la proporción de los indicadores es de 13/25, lo cual es muy bajo, lo que definitivamente tiene incidencia directa sobre el impacto ambiental.
En cuanto a la proporción relacionada con el tratamiento que se da en los hogares, el índice genera tan solo un punto de los cinco posibles, lo cual es preocupante, y orienta a que se debe trabajar más 
formalmente con los valores, principios y actitudes pro ambiental de la sociedad de Cobán, Alta Verapaz. La Gráfica 4 muestra de mejor manera el comportamiento del impacto ambiental de los RS en Cobán:

\section{Gráfica 4 \\ Modelación gráfica del impacto ambiental de los RS en Cobán}

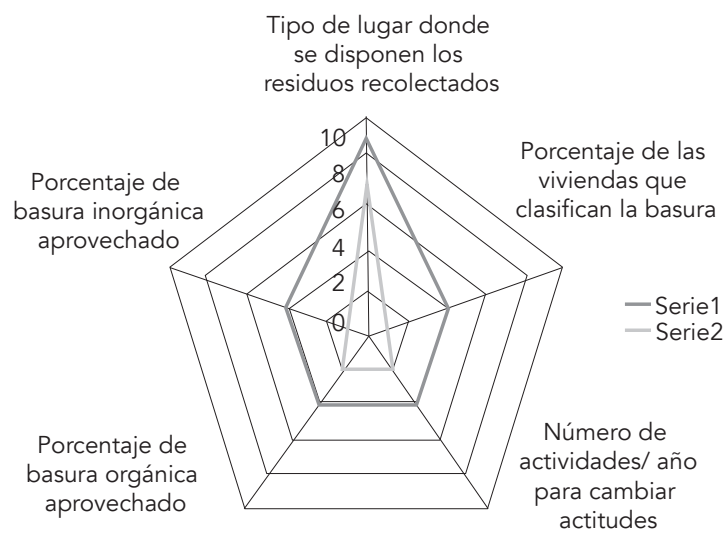

Fuente: Elaboración propia en base al IARNA, 2011

En relación al impacto ambiental, la Gráfica 4 muestra el comportamiento del manejo de las intervenciones hacia el ambiente relacionadas con la disposición, aprovechamiento de residuos orgánicos e inorgánicos, las viviendas que clasifican la basura y el número de actividades anuales relacionadas con la cultura ambiental, a través de la educación formal o informal, con el fin de promover los valores, actitudes y comportamientos pro ambientales.

Respecto a la disposición de los RS recolectados, se puede observar entre la serie 1 y la 2, gran diferencia, entre lo real y lo ideal. Se asigna un valor de los RS recolectados en relación al impacto ambiental asignado de 9 y el ideal para una completa GIRS, de 10, lo cual redunda en una intervención desmedida hacia el entorno natural y ambiental del área de Cobán.

Un tema importante de resaltar es que, aunque se cuenta con un lugar donde se depositan todos los RS no existe un sistema de disposición tanto de los residuos orgánicos como inorgánicos, con lo cual se generan altos grados de contaminación, por no tener ningún tratamiento, aprovechamiento, reciclaje y reutilización de los residuos sólidos.

\section{Conclusiones}

De acuerdo con la investigación realizada no existe una participación efectiva de la sociedad en la GIRS en Cobán, Alta Verapaz pues los habitantes de Cobán no manifiestan interés por el manejo integral adecuado de residuos sólidos en este municipio.

La gestión integrada de residuos sólidos en Cobán debe enfocarse en control de la generación, almacenamiento, recogida, transferencia y transporte, procesamiento y evacuación de residuos de una forma que armonice con los mejores principios de la salud pública, de la economía, de la ingeniería, de la conservación, de la estética y de otras consideraciones ambientales, y que también responde a las expectativas públicas.

El $30 \%$ de los habitantes de la ciudad de Cobán no contratan los servicios de recolección de RS, prefieren incinerarlos, enterrarlos, tirarlos a orillas de calles, fosas naturales y sitios retirados o transportarlos directamente al vertedero.

La mayoría de residentes de la ciudad de Cobán no perciben como problema los residuos sólidos, sino que lo califican como un problema ambiental y que se genera por la carencia de un sistema de gestión integrada por parte de la municipalidad y que debe institucionalizarse y ser dirigido por la misma.

El buen manejo de los RS y la búsqueda de la GIRS, debe recaer sobre los gobiernos municipales, quienes deberán organizar y administrar de manera correcta el proceso del tren de aseo público, incluyendo la infraestructura y los requerimientos necesarios para la disposición y tratamiento final.

Los resultados de la investigación indican esencialmente que la municipalidad de Cobán, carece de un sistema de gestión integrada de los desechos sólidos municipales y que solamente recolecta los 
RS que se generan en los establecimientos comerciales y mercados municipales, ya que por generar ingresos para la comuna, debe prestarles el mantenimiento, aunque éstos se mantienen un tiempo almacenados en contenedores de concreto y generan contaminación ambiental.

En Cobán, Alta Verapaz, el manejo de los residuos sólidos -GIRS- no se realiza de manera eficiente, ya que no existe obligatoriedad en los pobladores, generada por las autoridades municipales para que se contraten los servicios de las empresas recolectoras $y$, no se hace un manejo integrado de los desechos sólidos, ni en los hogares, ni por parte de las empresas recolectoras, las cuales solamente depositan la carga en el basurero municipal.

El manejo de los RS en la ciudad de Cobán es llevado a cabo por cuatro empresas recolectoras autorizadas por la municipalidad y prestan el servicio al $60 \%$ de los ciudadanos, con servicio privado costeado por los habitantes en cada vivienda y comercios particulares; sólo el $10 \%$ de los RS los presta la municipalidad con barrido de calles y recolección en comercios y mercados municipales.

La metodología empleada y desarrollada por IARNA es funcional para la certificación ambiental municipal pues resulta de un alto valor debido a que brinda datos precisos, que pueden facilitar la gestión integrada de los residuos sólidos como se realizó en el municipio de Cobán, por lo cual se puede concluir que es aplicable para los municipios con similares condiciones, en la República de Guatemala.

\section{Referencias bibliográficas}

AMSA (Autoridad para el manejo sustentable de la cuenca del Lago de Amatitlán, Gt). (2004). La cuenca y el Lago de Amatitlán. Guatemala: JADE.

Building Alliances for Policy Change. (1998). Washington, DC: Johns Hopkins University School of Advanced International Studies Program on Social Change and Development. (Lynch).
CALAS (2007). Escritos sobre Derecho Ambiental. Centro de Acción Legal Ambiental y Social de Guatemala. Guatemala, Centro América.

CEMAT (Centro Mesoamericano de Estudios sobre Tecnología Apropiada) (2004). Análisis integral nacional. Componente Guatemala.

CASE (Centro de Adiestramiento de Seguridad y Ecología) (2015). Manual de capacitación "curso básico de seguridad y ecología". México: PEMEX exploración y producción región sur.

Careaga, J. A. (1993) Manejo y Reciclaje de los Residuos de Envases y Embalajes. Chile.: Sedesol. Instituto Nacional de Ecología. Serie Monografías No. 4.

Espinoza, H. (2013). Plan de manejo para la parte alta de la subcuenca del río Jalapa, con énfasis en el análisis de tres componentes: Aguas residuales y Desechos Sólidos, manejo y conservación del suelo y gestión de riesgo, Jalapa 2012. Investigación Inferencial, Ingeniero Agrónomo. CUNSURORI-USAC

FIPA-USAID (2001). Documento de apoyo para elaboración de política marco de gestión ambiental. Guatemala. MARN.

ICONTEC. (2009). GTC 24: Guía para la separación en la fuente (Gestión ambiental: Residuos sólidos). Guía técnica colombiana (GTC). Bogotá: Instituto Colombiano de Normas Técnicas y Certificación.

IARNA (Instituto de Agricultura, Recursos Naturales y Ambiente) (2011). Municipios sostenibles en Guatemala; Perfil Socioambiental de Tecpán, Chimaltenango. Guatemala: Universidad Rafael Landívar, Facultad de Ciencias Ambientales y Agrícolas, IARNA.

IARNA (Instituto de Agricultura, Recursos Naturales y Ambiente) (2010). Perfil Ambiental de Guatemala: Tendencias y reflexiones sobre la gestión ambiental. Guatemala: Universidad 
Rafael Landívar, Facultad de Ciencias Ambientales y Agrícolas, IARNA.

IARNA (2009a). Perfil ambiental de Guatemala 2008-2009: las señales ambientales críticas y su relación con el desarrollo. Ciudad de Guatemala (Guatemala): Universidad Rafael Landívar, Facultad de Ciencias Ambientales y Agrícolas, IARNA.

IARNA (Instituto de Agricultura, Recursos Naturales y Ambiente) (2009b). Gestión ambiental y gobernabilidad local. Ciudad de Guatemala (Guatemala): Universidad Rafael Landivar, Facultad de Ciencias Ambientales y Agrícolas, IARNA e INGEP.

IARNA (Instituto de Agricultura, Recursos Naturales y Ambiente) (2006). Perfil ambiental de Guatemala: tendencias y reflexiones sobre la gestión ambiental. Ciudad de Guatemala (Guatemala): Universidad Rafael Landívar, Facultad de Ciencias Ambientales y Agrícolas, IARNA.

IARNA (Instituto de Agricultura, Recursos Naturales y Ambiente) (2004). Perfil ambiental de Guatemala: informe sobre el estado del ambiente y bases para su evaluación sistemática. Ciudad de Guatemala (Guatemala): Universidad Rafael Landívar, Facultad de Ciencias Ambientales y Agrícolas, IARNA.

INE (Instituto Nacional de Estadística). (2003). "Censo Nacional Agropecuario". Ciudad de Guatemala (Guatemala): INE-MAGA.

INE (Instituto Nacional de Estadística). (2002). "Encuesta nacional sobre condiciones de vida: perfil de la pobreza en Guatemala". Ciudad de Guatemala (Guatemala): INE.

Instituto Geográfico Nacional (1985). Hojas Cartográficas de la República de Guatemala. Guatemala: IGN.

JICA (1995). Análisis de la gestión de residuos. Guatemala. Ed. JICA. (Agencia de Cooperación de Japón).
Kiely Gerard, (2001) Ingenieria ambiental, Fundamentos, Entornos, Tecnologías y sistemas de gestión. España: Mc Graw Hill

Leff., E. (2004). Racionalidad Ambiental: la reapropiación social de la naturaleza. México: Siglo XXI Editores.

Lind, D. et al., (2008) Estadística aplicada a los negocios y la economía. México. McGraw-Hill/ Interamericana Editores, S.A. de C.V.

Lozano., M. et al. (2007). An analysis of the implementation of an environmental management system in a local public administration. País: Journal of Environmental Management.

MARN (Ministerio de Ambiente y Recursos Naturales) (2009) Informe Ambiental del Estado de Guatemala. GEO Guatemala.

MARN. Ministerio de Ambiente y Recursos Renovables (2001). Situación y evaluación de la calidad ambiental en Guatemala: Diagnóstico y propuestas de solución. Guatemala:

MARN. (2003). Situación y evaluación de la calidad ambiental en Guatemala. Diagnóstico y propuestas de solución). Guatemala.

MARN. (2004). Situación y evaluación de la calidad ambiental en Guatemala. Diagnóstico y propuestas de solución. Guatemala:

MARN. (2005). Situación y evaluación de la calidad ambiental en Guatemala. Diagnóstico y propuestas de solución. Guatemala.

Martínez Alier, J. (2006). El ecologismo de los pobres, conflictos ambientales y lenguajes de valoración. (2da Ed), Barcelona (España): Icaria.

Martínez, J. (2002). Determinación Cualitativa y Cuantitativa de los Niveles de Contaminación por Desechos Sólidos Orgánicos e Inorgánicos y la Aplicación de Aboneras para la Producción de Compost como una Alternativa viable en el Manejo de los Desechos Orgáni- 
cos Producidos en la ciudad de Jalapa. Tesis. Ingeniero Agrónomo. CUNSURORI, JALAPA.

Mijangos, N. (2002). Manejo integral de desechos sólidos del complejo de parques del Instituto de Recreación de los trabajadores IRTRA. Parque acuático Xocomil, y temático Xetulul. Guatemala. Tesis. Lic. Biología. Universidad del Valle de Guatemala.

Muñoz, H. (1985). Disposición de basuras en localidades de escasos recursos económicos. Tesis Ing. Civil. Guatemala, Gua. Facultad de Ingeniería, Universidad de San Carlos de Guatemala. s.p.

Odum, E. (1986). Fundamentos de la ecología. México: Editorial Interamericana.

Oliva, B. y Pérez, J. (s.f.) La Contaminación del agua y su impacto en la salud de Guatemala. Facultad de Ciencias Químicas y Farmacia, Universidad de San Carlos de Guatemala. Guatemala: Editorial Universitaria.

ONU (2009). Indicadores de los Objetivos de Desarrollo del Milenio. Organización de Naciones Unidas, Guatemala.

OPS (Organización Panamericana de la Salud) (Gua.) (1994). Lineamientos técnicos para la elaboración de planes de aseo urbano. Guatemala, Gua. V.7, p.43.

Orellana, J. (2013). Diseño de planta de compostaje para el manejo de los desechos sólidos del municipio de San Manuel Chaparrón, Jalapa. 2013. Investigación Inferencial, Ingeniero Agrónomo. CUNSURORI-USAC

PAF-MAYA (2002). Informe de Plan de Acción Forestal Maya. Guatemala. Ed. PAF-MAYA.

PNUD (Programa de Naciones Unidas para el Desarrollo). (2009). Informe de desarrollo humano 2008. Guatemala. Editorial Sur.
PNUD (Programa de Naciones Unidas para el Desarrollo). (2007). Informe de desarrollo humano 2007. Guatemala: Editorial Sur.

PNUD (Programa de Naciones Unidas para el Desarrollo). (2005). Informe Nacional de desarrollo humano. Diversidad étnico-cultural: La ciudadania en un estado plural. Guatemala: Edit. Sur, S.A.

Recinos, Y. (2014). Educación ambiental en el área de salud para el manejo de los desechos sólidos hospitalarios; el caso de los Centros de Atención Permanente -C.A.P.- en el departamento de Jalapa, Guatemala. Tesis de Maestría. CUNSURORI-USAC

Reyes, R. (s.f.) Biodiversidad y Amenazas. Cap. 11. Guatemala: CONAP.

Tchobanogloous G., et al. (1998). Gestión integral de residuos sólidos. España, Mc Graw Hill, Volumen I y II.

Van de Kludndert, A. y J. Anschultz. (2001) Integrated sustenaible waste management-the concept. Tools for decisión makers experience from urban waste expertise programe. Series. Ed. Anne Sheinberg. Netherlands.

Vargas, J. (2008). Basura Cero: Una alternativa sustentable. Disponible en http://www.ecoportal.net/content/view/full/55022. Consultado (junio 15 del 2008).

Villanueva, M. (2008). Determinación cualitativa y cuantitativa de los desechos sólidos en la ciudad de Monjas, Jalapa. Investigación Inferencial, Ingeniero Agrónomo. CUNSURORI-USAC

Zorrilla, M. (2005). La influencia de los aspectos sociales sobre la alteración ambiental y la restauración ecológica. In Eds. Sánchez, O; et al. Temas sobre restauración ecológica. México: Instituto Nacional de Ecología. 